\title{
Correction to: Enhanced Electrocatalytic Activity of Non-metal-Doped Transition Metal Oxides for an Electrochemical Detection of Furazolidone
}

\author{
Dhanapal Vasu ${ }^{1}$ - Arjunan Karthi Keyan ${ }^{1}$. Subramanian Sakthinathan ${ }^{1}$. Chung-Lun $\mathrm{Yu}^{1} \cdot$ Bing-Zhen Hsu ${ }^{1}$. \\ Te-Wei Chiu ${ }^{1}$. Junsheng $\mathrm{Wu}^{2}$
}

Published online: 2 March 2022

(c) Springer Science+Business Media, LLC, part of Springer Nature 2022

Correction to: Electrocatalysis https://doi.org/10.1007/s12678-022-00715-9

Subramanian Sakthinathan and Junsheng Wu should also be captured as corresponding authors.

The original article has been corrected.

Publisher's Note Springer Nature remains neutral with regard to jurisdictional claims in published maps and institutional affiliations.

The original article can be found online at https://doi.org/10.1007/ s12678-022-00715-9.

Subramanian Sakthinathan

sakthinathan1988@gmail.com

$\triangle$ Te-Wei Chiu

tewei@ntut.edu.tw

$\triangle$ Junsheng Wu

wujs@ustb.edu.cn

1 Department of Materials and Mineral Resources

Engineering, National Taipei University of Technology,

Taipei 106344, Taiwan

2 Institute for Advanced Materials and Technology, University of Science and Technology Beijing, Beijing 100083, China 